\title{
A comparison of health related quality of life in schizophrenia and multiple sclerosis
}

\author{
Vasilis Bozikas*1, Vasiliki Holeva², Katerina Gamvrula², Anna Kafantari², \\ Vagelis Koutlas ${ }^{3}$, Amalia Alexiadou ${ }^{3}$, Kostas Fokas ${ }^{1}$ and \\ Athanasios Karavatos ${ }^{2}$
}

\begin{abstract}
Address: ${ }^{12}$ nd Department of Psychiatry, Aristotle University of Thessaloniki, Greece, ${ }^{2} 1$ st Department of Psychiatry, Aristotle University of Thessaloniki, Greece and ${ }^{3}$ Department of Neurology, Papageorgiou General Hospital, Greece

* Corresponding author
\end{abstract}

\author{
from International Society on Brain and Behaviour: 2nd International Congress on Brain and Behaviour \\ Thessaloniki, Greece. 17-20 November 2005 \\ Published: 28 February 2006 \\ Annals of General Psychiatry 2006, 5(SuppI I):S23I doi:I0.II86/I744-859X-5-SI-S23 I
}

\section{Background}

Schizophrenia and multiple sclerosis are different chronic brain diseases that seriously affect quality of life of a person's life. Assessing health related quality of life (HRQoL) could provide with valuable information health care professionals in order to treat patients with chronic medical conditions more efficiently. The main aim of this study is to compare quality of life of patients suffering multiple sclerosis versus schizophrenic patients.

\section{Materials and methods}

A total of 68 patients, participated in the study divided into two groups: the group with patients suffering schizophrenia $(n=38$, mean age: $36.28 \pm 9.61)$ and the group comprised with patients suffering multiple sclerosis $(\mathrm{n}=$ 30 , mean age: $36.68 \pm 11.72$ ). The two groups differed significantly in three demographic variables: sex $(\mathrm{x} 2=5.83$, $\mathrm{p}=0.014)$, years of education $(\mathrm{F}=4.26, \mathrm{p}=0.043)$ and years of disease $(F=6.70, p=0.012)$. Short Form Health Survey (SF-36) was used to assess quality of life. This is a generic health instrument that measures patient's physical functioning, bodily pain and perception of ability to perform physical, emotional, and social role functions, as well as sense of vitality, mental health and general health plus 1 item assessing a change in health over the past year. Designed for use in surveys of general and specific populations, health policy evaluations and clinical practice and research, the survey can be self-administered by people 14 years of age or older, or administered by trained interviewers either in person or by telephone.

\section{Results}

Significant differences were only found between the two groups regarding Mental Summary $[\mathrm{F}(1,63)=8.90, \mathrm{p}=$ $0.004]$, and the subscales of Physical Functioning $[F(1,63)$ $=11.44, \mathrm{p}=0.001]$, Vitality $[\mathrm{F}(1,63)=63.91, \mathrm{p}<0.001]$, after controlling for sex, education and yeas of disease.

\section{Discussion}

Both groups presented similarly impaired QoL. MS group showed higher deficit in Physical Functioning, Vitality and Mental Component Summary, possibly due to the complex nature of MS that affects patients' well-being both physically and psychologically. 